\title{
Aplicación de la Búsqueda Armónica para el problema de formación de celdas de manufactura
}

\section{A Harmony Search approach for the Manufacturing Cell Design Problem}

\author{
DOI: http://doi.org/10.17981/ingecuc.15.2.2019.15
}

Artículo de Investigación Científica. Fecha de Recepción: 7/12/2018. Fecha de Aceptación: 24/09/2019

\author{
Edwin Alberto Garavito Hernández (i) \\ Universidad Industrial de Santander. Bucaramanga (Colombia) \\ garavito@uis.edu.co \\ Leonardo Hernán Talero Sarmiento (i) \\ Universidad Industrial de Santander. Bucaramanga (Colombia) \\ leonardo.talero@correo.uis.edu.co \\ Laura Yeraldín Escobar Rodríguez \\ Universidad Industrial de Santander. Bucaramanga (Colombia) \\ laura.escobar@correo.uis.edu.co
}

Para citar este artículo:

E. Garavito Hernández, L. Talero Sarmiento y L. Escobar Rodríguez, "Aplicación de la Búsqueda Armónica para el problema de formación de celdas de manufactura”, INGE CUC, vol. 15, no. 2, pp. 155-167, 2019. DOI: http://doi.org/10.17981/ingecuc.15.2.2019.15

\section{Resumen}

Introducción- La Manufactura Celular (MC) es una aplicación de la tecnología de grupos consistente en la agrupación de familias de productos y la formación de familias de máquinas, mediante la descomposición de un sistema de manufactura complejo en subsistemas que atienden las operaciones de familias enteras de productos. A partir de un modelo de programación lineal entera que integra costos de producción con costos por transferencias entre celdas se propone un método de solución denominado algoritmo de Búsqueda Armónica.

Objetivo- Determinar el desempeño de la Búsqueda Armónica modificada y las variantes de asignación de máquinas al problema de formación de celdas de manufactura.

Metodología- Se desarrolla un modelo matemático de programación entera, utilizando variables binarias para determinar la asignación de las operaciones de diversos productos a distintas máquinas en diferentes celdas, con variables enteras para cuantificar los requerimientos de las máquinas y la cantidad de transferencias entre las celdas. La validación del modelo se hace utilizando instancias modificadas de la literatura en el software GAMS usando el solver CPLEX y en MATLAB se perfecciona el algoritmo metaheurístico para dar solución aproximada.

Resultados- Se encuentra que las variantes propuestas integradas en la Búsqueda Armónica logran buenos resultados aprovechando el enfoque de explotación del espacio de búsqueda.

Conclusiones- A partir de las variantes aplicadas se logró encontrar muy buenas soluciones en tiempos considerablemente cortos, pero no obstante, es necesario implementar estrategias de exploración del espacio de búsqueda con el fin de evitar caer en óptimos locales.

Palabras clave- Búsqueda Armónica; Diseño de plantas; Manufactura celular; Metaheurísticas

\begin{abstract}
Introduction- Cellular Manufacturing (CM) is an application of group technology consisting of the grouping of product families and the formation of machine families by breaking down a complex manufacturing system into subsystems that serve the operations of entire product families. Based on an integer linear programming model that integrates production costs with costs for transfers between cells, a solution method called Harmonic Search algorithm is proposed.
\end{abstract}

Objective- Determine the performance of the modified Harmonic Search and the variants of machine assignment to the manufacturing cell formation problem.

Methodology- A mathematical model of integer programming is developed, using binary variables to determine the assignment of the operations of various products to different machines in different cells, with integer variables to quantify the requirements of the machines and the amount of transfers between the cells. Model validation is done using modified instances of the literature in GAMS software using the CPLEX solver, and in MATLAB the metaheuristic algorithm is refined to give approximate solution.

Results- It is found that the proposed variants integrated in the Harmonic Search achieve good results by taking advantage of the search space exploitation approach.

Conclusions- From the applied variants it was possible to find very good solutions in considerably short times, but nevertheless it is necessary to implement strategies of exploration of the search space in order to avoid falling into optimal premises.

Keywords- Harmony Search; Facility Layout; Cellular manufacturing, Metaheuristic 


\section{INTRODUCCIÓN}

En un entorno globalizado se hace necesario que las empresas adopten estrategias que les permitan ser competitivas y permanecer vigentes en el mercado, y de esta manera, conocer la competencia, producir lo que el mercado demanda, alinear los procesos y recursos a la estrategia de la empresa, son entre otros, los factores que pueden representar una ventaja competitiva para cualquier organización. Adicionalmente, la automatización y la integración tecnológica (industria 4.0) han traído al mercado manufacturero cambios mucho más rápidos y mayores niveles de competitividad, dando mayor relevancia a la planeación de los aspectos relacionados con la producción, buscando mejorar los procesos de manufactura, atender las necesidades del mercado existente y disminuir los costos asociados a la fabricación.

Adicionalmente, los sistemas de manufactura basan gran parte de su eficiencia en una adecuada organización física de los recursos para la producción, permitiendo adecuados flujos de trabajo y la posibilidad de cumplir con los requerimientos que la demanda les exige. Una distribución de planta adecuada y sostenible es capaz de manejar las variaciones y se considera un primer paso hacia la Industria 4.0, buscando mantener la fabricación de los productos requeridos en el momento oportuno, generando de esta manera una ventaja competitiva para las organizaciones [1]. En los diseños de manufactura, dos grandes tipos de distribución suelen ser desarrollados de manera dicotómica: la distribución de planta, orientada a talleres de trabajo se caracteriza por su flexibilidad tanto en variedad de productos como en capacidad, gracias al alto volumen de productos en proceso y de otra parte, el diseño orientado a líneas de producción, que ofrece comparativamente un mayor nivel de eficiencia, además de ofrecer beneficios asociados a la reducción de costos y disminución de las dificultades que generan los inventarios en proceso, en la medida en que éstos se reducen sustancialmente con ese enfoque en el diseño. La configuración en sistemas de manufactura celular es una alternativa que se beneficia de la flexibilidad característica de los talleres, y las bondades de las líneas de producción convencionales, siendo viable en empresas con niveles de demanda media y condiciones de mercado que le exigen respuestas eficientes con menores tiempos de suministro.

En ese sentido, la Manufactura Celular-MC (Cellular Manufacturing, CM) es una aplicación de la tecnología de grupos dirigida al manejo de problemas estructurales en las compañías para reducir costos de operación, tiempos de suministro y tiempos de preparación, entre otros [2]. Para aplicar la MC se realiza el agrupamiento de productos similares en familias y las máquinas requeridas para su fabricación en celdas [3]. Sin embargo, la MC es también la integración de recursos, personal, tiempo, espacio e información, con el propósito de atender las necesidades de un determinado grupo de partes y de sus tareas correspondientes [4].

Ahora bien, para diseñar una MC se deben resolver dos problemas [5]. El primero, construir familias de productos, teniendo en cuenta características físicas tales como tamaños, formas, pesos o requerimientos de proceso similares. Y el segundo, formar familias de máquinas (celdas) para la creación de grupos de máquinas (generalmente disímiles) para la fabricación de familias de productos conformadas, descomponiendo un sistema de manufactura complejo en subsistemas menores, los cuales atienden las operaciones de familias enteras de productos, en los que el flujo de éstos, la secuenciación de los trabajos, la planeación de la capacidad y los procedimientos de control se simplifican, generando beneficios como: reducción de tiempos de preparación, tiempos de espera, inventarios, etcétera, y buscando minimizar costos de producción y aumentando el nivel de servicio [6]-[8].

Como consecuencia de lo anterior, al tener en cuenta la agregación de subproblemas se conforma un sistema global complejo, el cual, dependiendo de los elementos que lo conforman, requerirá de métodos de solución específicos, por tanto, en esta investigación se desarrolla un modelo matemático de programación lineal entera que integra costos de producción con costos por transferencias entre celdas. Ahora bien, la incorporación de una formulación matemática resulta acertada desde el punto de vista práctico en el desarrollo de soluciones, pero desde el punto de vista de la eficiencia computacional en términos de los tiempos y esfuerzos para llegar a los resultados, no resultan razonables. En consecuencia, se puede identificar en la literatura una tendencia clara, recomendando la generación de modelos y métodos de tipo heurístico que permitan ser adaptados a las formulaciones matemáticas más complejas, proporcionando soluciones factibles y prácticas en tiempos de ejecución menores. De acuerdo a lo anterior, se propone como método de solución un algoritmo metaheurístico denominado Búsqueda Armónica-BA (Harmony Search, HS) [9] el cual ha presentado buenos resultados en problemas de programación de la producción [10], [11], [12], [13] y no ha sido implementado en problemas de formación de celdas de manufactura. 


\section{REVISIÓN LITERARIA}

El diseño de sistemas de manufactura celular implica la organización de sistemas en celdas y la determinación del tipo y del número de recursos necesarios en cada una para la satisfacción de sus requerimientos, lo cual es computacionalmente complejo [3]. Dependiendo de la naturaleza y complejidad de las celdas de manufactura es posible agrupar las técnicas de solución en dos grandes grupos como se expone en la Fig. 1. El primero, producción orientada al diseño, para el agrupamiento de máquinas desde elementos físicos a codificaciones específicas, y el segundo, producción orientada al flujo, la cual aborda diversas técnicas matemáticas.

El primer método de solución se divide en dos grandes categorías: En primer lugar, clasificación visual, para agrupar teniendo en cuenta atributos como forma, dimensiones, materias primas, tolerancias y operaciones requeridas, entre otros [2]. De otra parte, la clasificación por codificación, para agrupar utilizando una clasificación simbólica mediante un código jerárquico, no jerárquico o híbrido, que tiene entre 10 y 30 dígitos y que representa sus atributos característicos [2], [6], [8].

El segundo método de solución está conformado por tres categorías. La primera es por agrupamiento (el cual incluye dos enfoques), el enfoque matricial, donde existen tres tipos principales de algoritmos:
Bond Energy Algorithm, Direct Clustering Algorithm y Rank Order Clustering [14], [15]; y el enfoque por similitud, con algoritmos derivados de la taxonomía numérica usando coeficientes de Jaccard [2], coeficientes basados en tamaño de lote [16] y coeficientes de productos de programación [17], aplicados con métodos jerárquicos [18], [19] y no jerárquicos como ISNC, ZODIAC y GRAFICS [20]-[22]. La segunda categoría es programación matemática (resaltando cuatro enfoques), el enfoque P-means (P-medias), método usado para agrupar productos en familias de productos con el objetivo de minimizar la suma total de las distancias entre cualquier par de tipos de producto [23]; el enfoque de formación de celdas Flow-Shop, método usado para la descomposición del problema general job shop, en múltiples sistemas pseudo flow shop [24]; el enfoque por agrupamiento simultáneo de partes $y$ maquinas, método enfocado en la solución mediante pasos subsecuentes: el primer paso computa el tamaño de lote y número de mínimo de máquinas y el segundo paso es una formulación matemática para minimizar costos de transferencias intercelulares y de modificación de las máquinas; y el enfoque de optimización multiobjetivo, el cual sigue una estructura similar al de agrupamiento simultáneo de partes y máquinas con la salvedad de poseer más de un objetivo y que éstos presentan conflictos entre sí y, por tanto, no se llega a una solución única sino se obtienen diferentes soluciones de Pareto [25], [26].

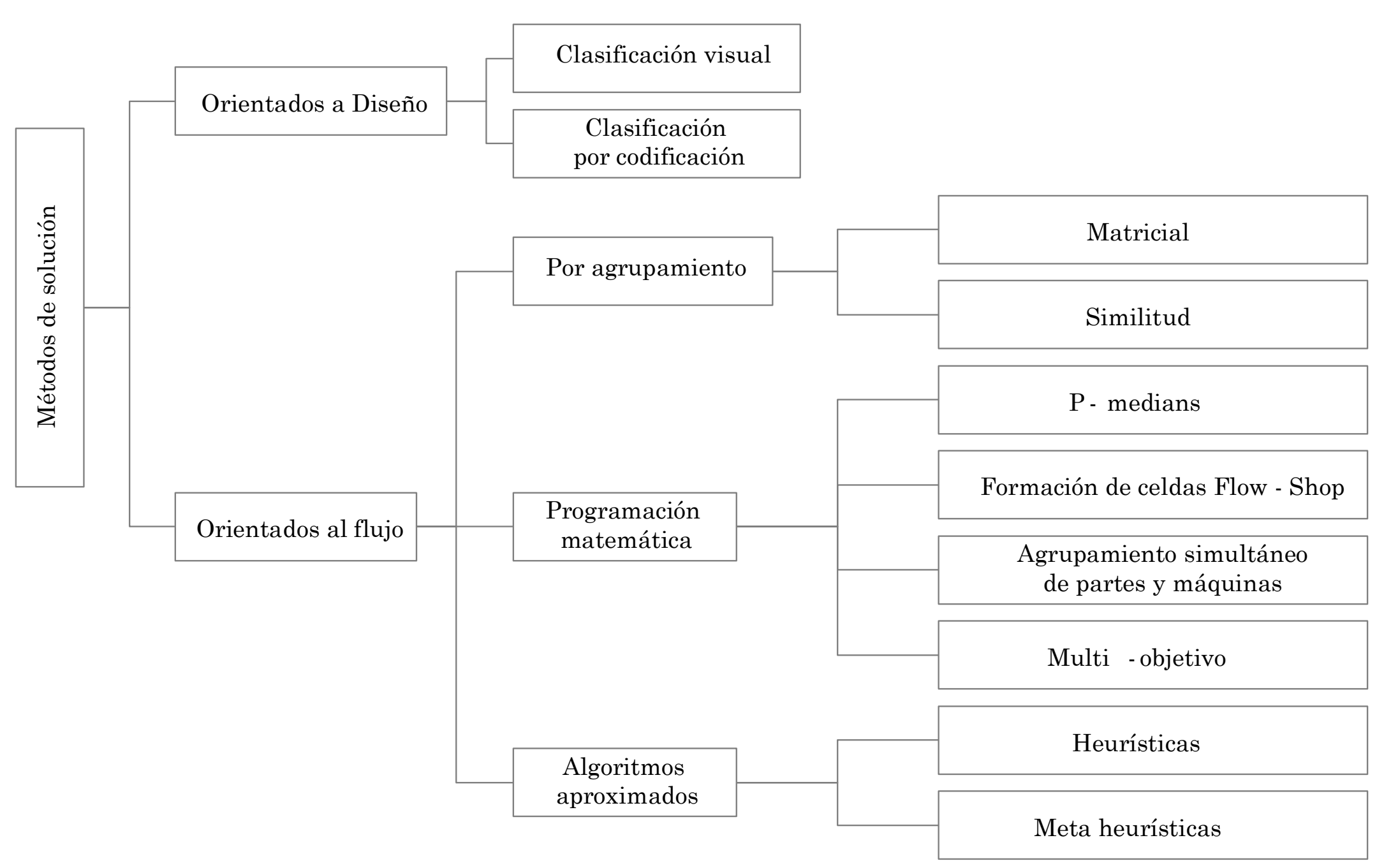

Fig. 1. Métodos de solución para la formación de celdas de manufactura. Fuente: Autores. 
Finalmente, la última categoría de algoritmos aproximados, agrupa dos enfoques, el enfoque por heurísticas, método común en aplicaciones prácticas para la solución de problemas en entornos de manufactura con limitaciones en la definición de restricciones (no pueden modificarse), y con la característica de no garantizar soluciones óptimas [27], [28]; y en último lugar el enfoque por Metaheuristicas, métodos encaminados en la solución aproximada de problemas de optimización combinatoria tipo NP y NP-Hard, debido a la dificultad para solucionarlos por métodos exactos. Entre los métodos de solución más comunes están Redes neuronales artificiales, lógica difusa, algoritmos genéticos [29]-[34], recocido simulado [30], [35]-[38], algoritmos de búsqueda dispersa [39], [40], búsqueda en el vecindario variable [41], [42] a model for a multi-period cellular manufacturing system (CMS, búsqueda tabú [43], [44], optimización por enjambre de partículas [45], [46] y técnicas hibridas entre otras [47]-[49].

\section{Modelo Matemático Propuesto}

El Modelo matemático utiliza la estrategia de agrupamiento simultáneo de productos y máquinas, asignando individualmente cada operación a una determinada celda y definiendo la cantidad de máquinas que correspondan para el cumplimiento de la demanda con el objetivo de minimizar el costo total; éste último compuesto por los costos de máquinas y el costo de transferencia de material entre celdas. La estructura general del modelo [7], [50], [51], no obstante, se propone una estructura lineal mediante la generación de variables auxiliares para contabilizar los movimientos de material entre celdas.

\section{A. Supuestos del modelo}

- Los parámetros definidos como datos de entrada son constantes y conocidos

- La totalidad de la demanda debe ser satisfecha a lo largo del periodo

- El tiempo de producción de un lote de producto por operación por tipo de producto incluye, de haberlo, el tiempo de alistamiento de máquina

- El transporte de los productos entre las celdas se hace por lotes y no requiere tiempo adicional

- El costo de transportar un lote de cualquier producto entre cualquier par de celdas no depende de la distancia recorrida

- Las máquinas de cada tipo son consideradas réplicas con idéntica capacidad e idéntico costo

- Las máquinas dentro del sistema están disponibles desde el comienzo del periodo

- Cada máquina dentro del sistema puede procesar una pieza a la vez
- La capacidad de las máquinas en el sistema es cien por ciento confiable

- No se consideran productos defectuosos ni paradas de máquina

- Los re-procesos no son permitidos en la operación del sistema

- No se consideran tiempos de espera en producción

- No se considera mantenimiento de inventarios

- No se considera el valor del dinero en el tiempo a lo largo del periodo

B. Índices

c: $\quad$ Índice para las celdas de manufactura $(c=1, \ldots, C)$.

$m: \quad$ Índice para los tipos de máquina $(m=1, \ldots, M)$.

$p: \quad$ Índice para los tipos de producto $(p=1, \ldots, P)$.

$j$ : $\quad$ Índice para las operaciones requeridas por el producto $p(j=1, \ldots, O p)$.

\section{Parámetros o datos de entrada}

$D_{p}$ : $\quad$ Demanda del producto $p$ para el periodo en número de lotes.

$a_{j p m}: \quad 1$, si la operación $j$ del producto $p$ es fabricada en la máquina tipo $m$. 0 , de lo contrario.

$t_{j p}$ : Tiempo de operación requerido para completar la operación $j$ en un lote del producto tipo $p$ (incluido el tiempo de alistamiento de máquina).

$C A P_{m}$ : Capacidad disponible de una máquina tipo $m$ durante el periodo.

$C M_{m}$ : Costo de tener una máquina tipo $m$ durante el periodo.

CTI: Costo de transferir un lote de cualquier producto entre cualquier par de celdas.

$T_{\text {min }}$ : Número mínimo de máquinas por celda.

$T_{m a x}: \quad$ Número máximo de máquinas por celda.

D. Variables de decisión

$N_{m c}$ : Número de máquinas tipo $m$ a asignar a la celda $c$ durante el periodo.

$X_{j p c}: \quad 1$, si la operación $j$ del producto $p$ es asignada a la celda $c$. 0 , de lo contrario.

$Y_{j p c}^{+}$: Variable auxiliar para contabilizar los movimientos de material entre celdas teniendo en cuenta el proceso $j$, del producto $p$ en la celda $c$.

$Y_{j p c}: \quad$ Variable auxiliar para contabilizar los movimientos de material entre celdas teniendo en cuenta el proceso $j$, del producto $p$ en la celda $c$. 


\section{E. Formulación del modelo}

Una vez declarados los supuestos y definidos los índices, parámetros y variables auxiliares, se describe el modelo a partir de las siguientes ecuaciones:

$$
\begin{aligned}
& \operatorname{Min}\left\{T C=\sum_{C=1}^{C} \sum_{m=1}^{M} N_{m c} C M_{m}+C T I\left[\sum_{p=1}^{P} D_{p}\left(\sum_{j=1}^{O p-1} \sum_{C=1}^{C} Y_{j p c}\right)\right]\right\}(1) \\
& \sum_{C=1}^{C} X_{j p c}=1 \forall j y \forall p \\
& \sum_{p=1}^{P} \sum_{j=1}^{O p} D_{p} t_{j p} a_{j p m} X_{j p c} \leq C A P_{m} N_{m c} \forall m y \forall c \\
& \sum_{m=1}^{M} N_{m c} \geq T_{m i n} \forall c \\
& \sum_{m=1}^{M} N_{m c} \leq T_{m a x} \forall c \\
& X_{(j+1) p c}-X_{j p c}=X_{j p c}^{p o s}-X_{j p c}^{n e g} ; \forall j, \forall p, \forall c \\
& X_{j p c} \in[0,1] \\
& N_{m c}, Y_{j p c}^{+}, Y_{j p c}^{-} \geq 0
\end{aligned}
$$

La función objetivo (1) minimiza la suma total de dos costos: el primer término calcula el costo total de tener máquinas en el sistema y el segundo término representa el costo total de las transferencias de lotes de productos entre las celdas, éste último se modela mediante la variable auxiliar propuesta ya que representan las transferencias intercelulares del producto tipo $p$ en la celda $c$ entre las operaciones $j$ y $(j+1)$. El conjunto de restricciones (2) limita la asignación de cada operación de cada tipo de producto a una sola celda dentro del sistema. El conjunto de restricciones (3) garantiza que las capacidades de cada tipo de máquina y cada celda en el sistema no sean excedidas y que puedan satisfacer los requerimientos de la demanda. Los conjuntos de restricciones (4) y (5) establecen que el número de máquinas por cada celda no puede ser ni menor al valor establecido como mínimo, ni mayor al valor establecido como máximo. Los conjuntos de restricciones (6) representan las transferencias intercelulares del producto tipo $p$ en la celda $c$ entre las operaciones $j \mathrm{y}(j+1)$, y según [52], podrían definirse de la siguiente forma: $Y_{j p c}^{+}: 1$, si $X_{(j+1) p c}-X_{j p c}=1$, 0 en otro caso; $Y_{j p c}$ : 1 , si $X_{(j+1) p c}-X_{\mathrm{jpc}}=-1,0$ en otro caso. Finalmente, los conjuntos de restricciones (7) y
(8) señalan la naturaleza de las variables de decisión dentro del modelo, siendo las $X_{j p c}$, variables binarias y $N_{m c}, Y_{j p c}^{+}$y $Y_{j p c}^{-}$, variables enteras positivas respectivamente.

\section{Formulación del Algoritmo Búsqueda Armónica}

La búsqueda armónica, es un algoritmo metaheurístico basado en una población, por tanto, múltiples armonías (individuos) pueden ser seleccionadas en paralelo. Este recurso usado apropiadamente tiende a obtener un mejor rendimiento con una alta eficiencia puesto que, el proceso de improvisación no realiza cálculos matemáticos complejos generando un procesamiento rápido, lo cual hace que el tiempo de convergencia del algoritmo marque la diferencia entre los diferentes algoritmos metaheurísticos existentes [53], con características adicionales como el hecho de obviar óptimos locales y la posibilidad de manejar variables discretas y continuas.

La BA representa el proceso de improvisación musical [9], en el cual la experiencia y el previo conocimiento de las armonías aportan a la calidad de la pieza musical resultante. La BA busca producir una armonía agradable determinada por el estándar estético auditivo [53]. Cuando un músico está improvisando, realiza una de las siguientes acciones:

- Toca alguna melodía conocida que ha aprendido con anterioridad (Memoria).

- Toca algo similar a lo mencionado en el punto anterior (Tono).

- Compone una nueva melodía a partir de sus conocimientos musicales para seleccionar de manera aleatoria nuevas notas (Improvisación).

En la improvisación musical, cada músico toca una nota dentro de un posible rango (formando un vector armónico). Si el conjunto de notas tocadas por los músicos es considerado una buena armonía (Solución factible), ésta es guardada en la memoria de cada músico, incrementando la posibilidad de hacer una buena armonía la próxima vez. Cada nota es el valor de una variable de decisión (con valores aleatorios al inicio del algoritmo), formando un vector solución por cada improvisación musical $(\vec{x})$.

Si dicho vector, contiene una buena solución, ésta es almacenada, aumentando la posibilidad de encontrar mejores soluciones en la siguiente iteración. De acuerdo a lo anterior, desde el punto de vista algorítmico, la búsqueda armónica es un proceso iterativo y estocástico que construye, en cada iteración, un vector solución $(\vec{x})$ con fundamento en tres pautas básicas:

- Búsqueda en la matriz de memoria armónica

- Ajusta una solución previa por improvisación

- Búsqueda aleatoria 


\section{A. Estructura del metaheurístico}

$$
\min (\max ) f(x) \mid L B_{i}<x_{i}<U B_{i}
$$

Donde:

$$
\begin{array}{ll}
f(x): & \text { Función Objetivo } \\
x: & \begin{array}{l}
\text { Vector solución de longitud } N \\
\text { y } x_{i} \text { variables de decisión. }
\end{array} \\
L B_{i}, U B_{i}: & \begin{array}{l}
\text { Límites inferiores y superiores } \\
\text { para cada variable. }
\end{array}
\end{array}
$$

La BA se puede resumir en cuatro etapas. La primera es inicializar los parámetros del problema y los parámetros de BA: Primer parámetro, Tamaño de Memoria Armónica (Harmony Memory Size HMS) indica la cantidad de individuos de la población; Segundo parámetro, Tasa de Consideración de la Memoria Armónica (Harmony Memory Consideration Rate, HMCR) indica la probabilidad de seleccionar un individuo de la población; Tercer parámetro, Tasa de Ajuste al Tono (Pitch Adjustment Rate, PAR) determina la probabilidad de modificar un individuo seleccionado ajustando ligeramente los valores de cada $x_{i}$; y el Cuarto parámetro, Número de Improvisaciones es la cantidad de veces que evoluciona la población de armonías.

La segunda etapa es inicializar la memoria armóni$c a$, y para ello inicialmente se define a partir de una distribución uniforme en el intervalo $\left[L B_{i}, U B_{i}\right]$, donde $1 \leq i \leq N$; la tercera etapa es improvisar la nueva armonía, donde la improvisación hace referencia al proceso de generación de una nueva armonía, el nuevo vector armónico se genera utilizando la consideración de la memoria, ajuste del tono y selección aleatoria como reglas; y la cuarta etapa es actualizar la memoria armónica donde La nueva armonía $x_{i}^{\prime}=\left(x_{1}^{\prime}, x_{2}^{\prime}, \ldots, x_{N}^{\prime}\right)$, remplaza la peor armonía almacenada en la memoria armónica si el "fitness" (o valor de aptitud del vector armónico actual, medido en términos de la función objetivo) es mejor que la peor armonía.

\section{B. Parámetros del algoritmo metaheurístico}

Con el propósito de determinar los niveles de los parámetros a utilizar, se aplica el algoritmo BA a la función Himmelblau [54], una función multimodal, definida sobre $R^{2}$ y usada para comprobar el rendimiento de los algoritmos de optimización. Para ello se realizan 24200 corridas con el fin de observar el valor obtenido y su diferencia respecto al óptimo de la función, a partir de lo cual se definen los siguientes niveles para los parámetros del algoritmo:

$$
\begin{aligned}
& H M S=\{100,1000\} \\
& H M C R=\{50 \%, 90 \%\} \\
& P A R=\{10 \%, 50 \%\} \\
& N I \quad=\{100,5000\}
\end{aligned}
$$

\section{Estructura del algoritmo de solución}

En este trabajo se propone la configuración de cinco módulos en MATLAB 2017a relacionados con la ejecución de BA para la solución de un problema de asignación de celdas de manufactura. El primer Módulo (Fig. 2), está relacionado con la interfaz del usuario en la cual se asignan todos los parámetros de entrada y se obtiene la salida final de la metaheurística. El segundo Módulo (Fig. 3), está enfocado en la generación del vector de memorias armónico, para ello se ejecuta como subproceso el Módulo 3 y Módulo 4. El tercer Módulo (Fig. 4), es el encargado de generar las soluciones aleatorias para el problema propuesto, configurando las celdas con sus respectivas máquinas y actividades. El cuarto Módulo (Fig. 5), es el encargado de evaluar la Función Objetivo para crear el vector de resultados (costos) para cada valor en el vector de soluciones (Memoria armónica). Finalmente, el quinto Módulo (Fig. 6 ), es el encargado de ejecutar la metaheurística y generar las improvisaciones.

\section{Módulo 1: Principal}

Los diversos parámetros a utilizar son definidos en el Módulo 1 de la Fig. 2 y se dividen en dos grandes grupos: El primero, parámetros de la búsqueda armónica HMS, HMCR, PAR y NI. Y el segundo, parámetros del modelo matemático (Celdas y restricciones). Una vez definidos los parámetros se calcula los requerimientos de máquinas y se ejecuta el Módulo 2.

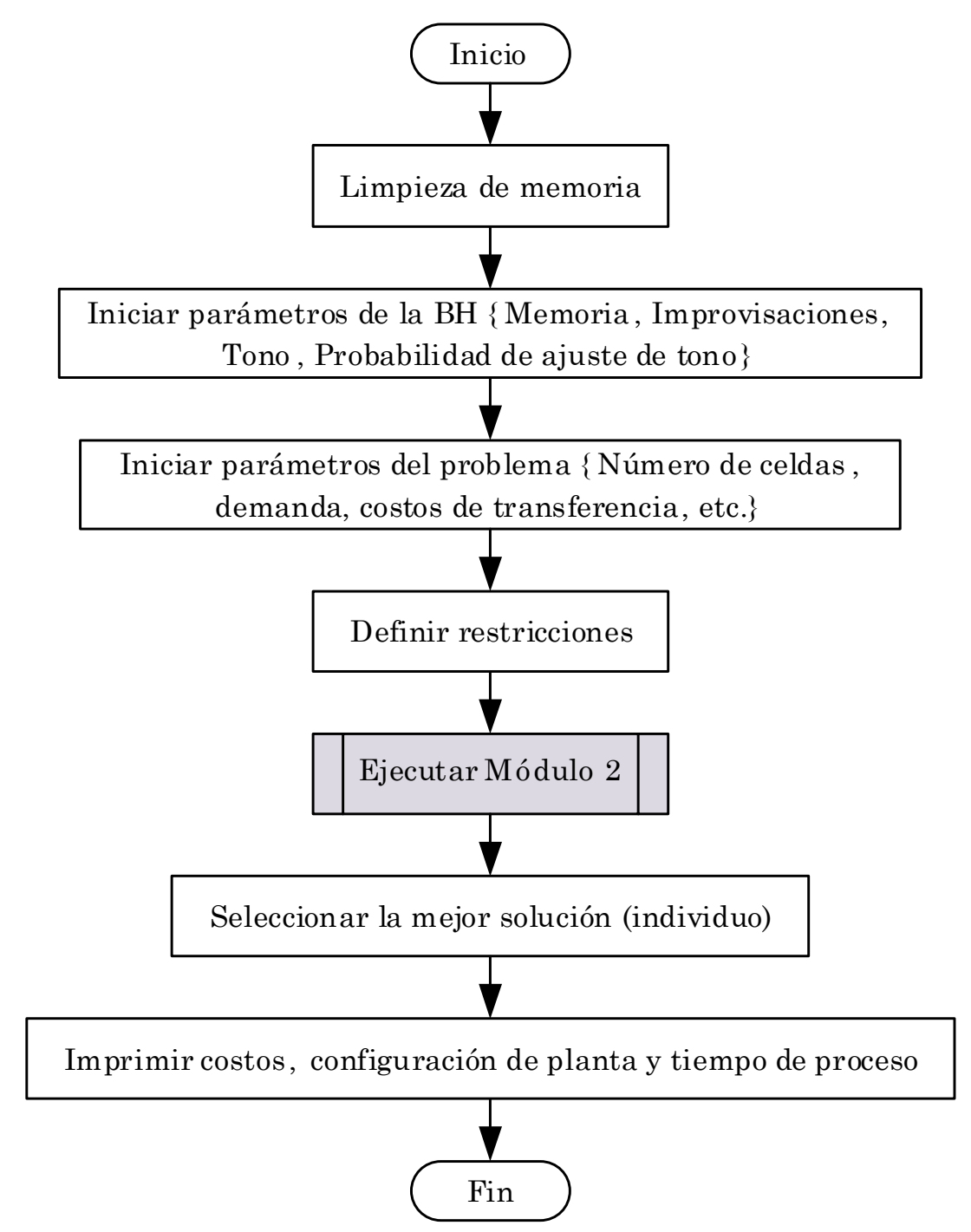

Fig. 2. Estructura del Módulo 1. Fuente: Autores. 


\section{Módulo 2: Generador de población}

De manera iterativa se crea el vector de soluciones ejecutando el Módulo 3, y posteriormente llamar al Módulo 5 para hacer la improvisación de la Fig. 3.

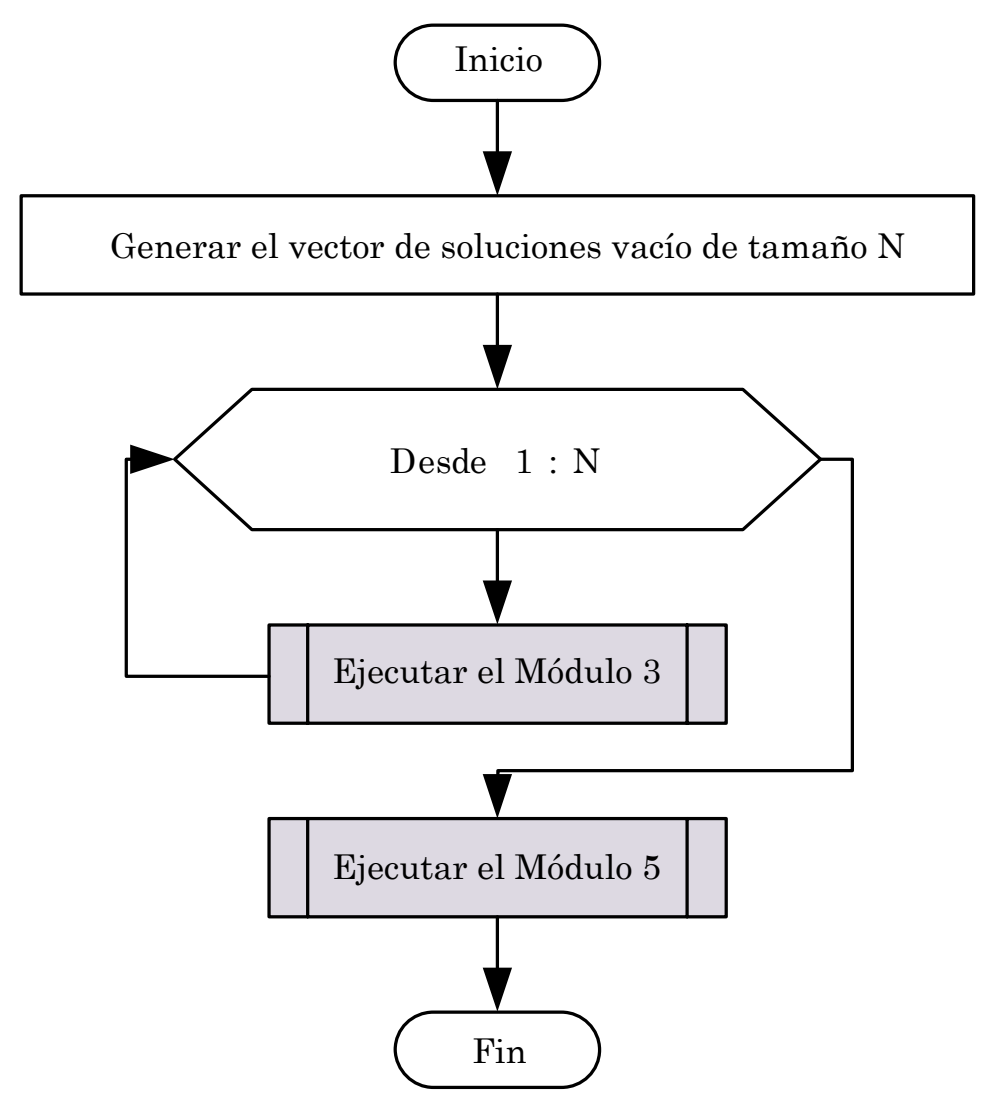

Fig. 3. Estructura del Módulo 2.

Fuente: Autores.

\section{Módulo 3: Generador de individuos}

En este módulo se generan las soluciones aleatorias a partir de la asignación estocástica de máquinas a cada celda. En la Fig. 4 se indica que primero se selecciona un tipo de máquina y se asigna una cantidad aleatoria de la misma a la primera celda, posteriormente, este proceso se repite en todas las celdas. Durante el presente trabajo se proponen dos estrategias de asignación; en la primera, el número de máquinas a asignar en cada celda se distribuye como una uniforme discreta entre cero y el número de máquinas requeridas en toda la planta $U\left[0, M A X_{m}\right]$ (Valor calculado en el Módulo 1), de tal forma que es posible asignar un número de máquinas mayor a la capacidad requerida.

En la segunda estrategia, el número de máquinas a asignar en cada celda se distribuye como una uniforme discreta entre cero y el número de máquinas faltantes por asignar $U\left[0, M A X_{m}-\right.$ Asignadas $\left._{m}\right]$, donde $M A X_{m}$ indica la cantidad máximas de máquinas requeridas por la planta y Asignadas ${ }_{m}$ es un contador que muestra cuántas máquinas se han asignado en las celdas previas, en consecuencia, la distribución uniforme presenta una cota superior dinámica que va disminuyendo a medida que se asignan máquinas, con esta propuesta se espera disminuir soluciones con capacidad ociosa. Una vez asignadas las máquinas de manera aleatoria, en la siguiente etapa se asignan los productos a fabricar y sus respectivos procesos a cada máquina en cada celda.

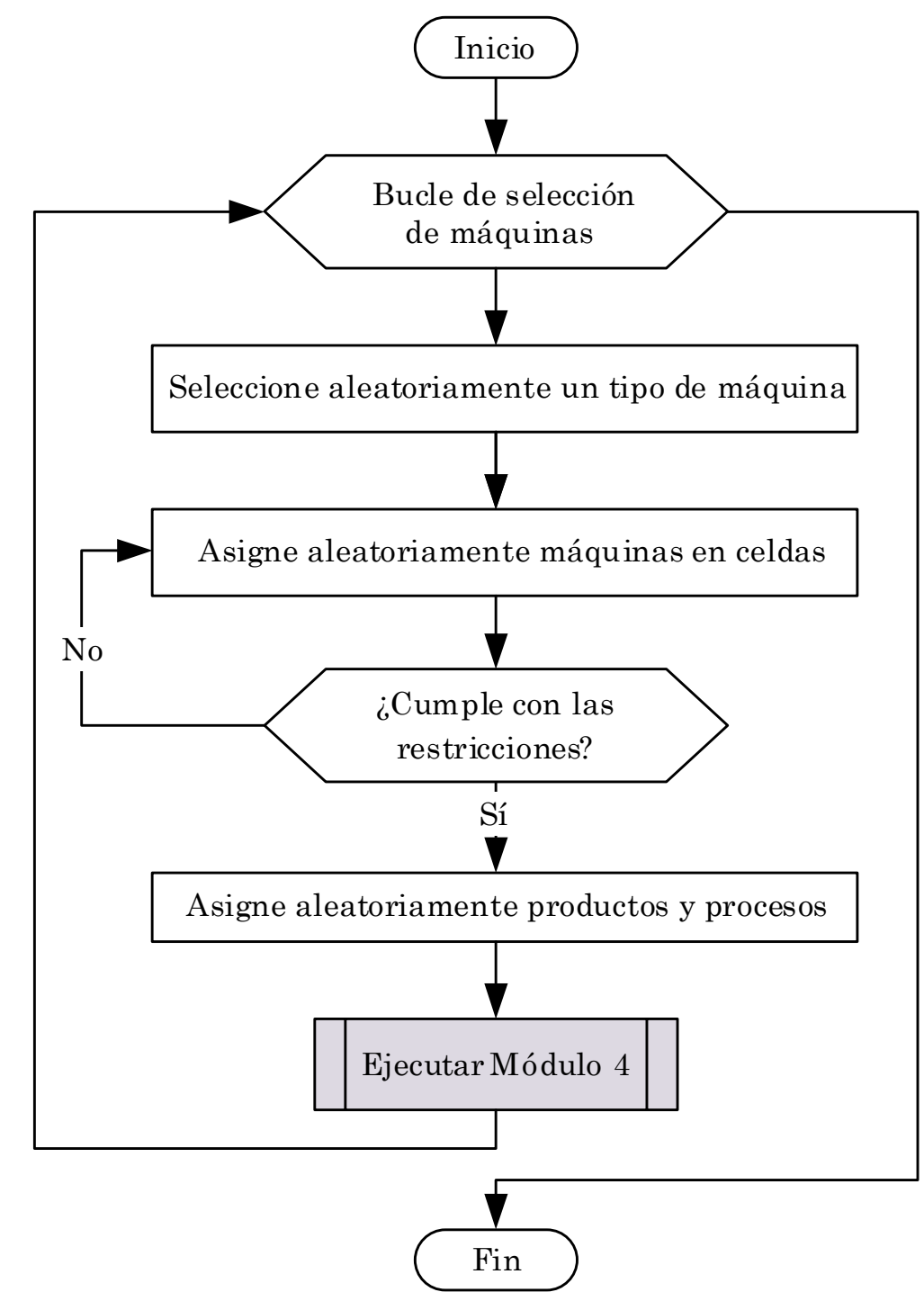

Fig. 4. Estructura del Módulo 3. Fuente: Autores.

\section{Módulo 4: Cálculo de la solución}

En el Módulo 4 (Fig. 5) se calcula el valor de la función objetivo, determinando y cuantificando la cantidad de operaciones calculando la cantidad de transferencias entre celdas y se multiplica por el costo de transferir, y se añade el costo de las máquinas requeridas.

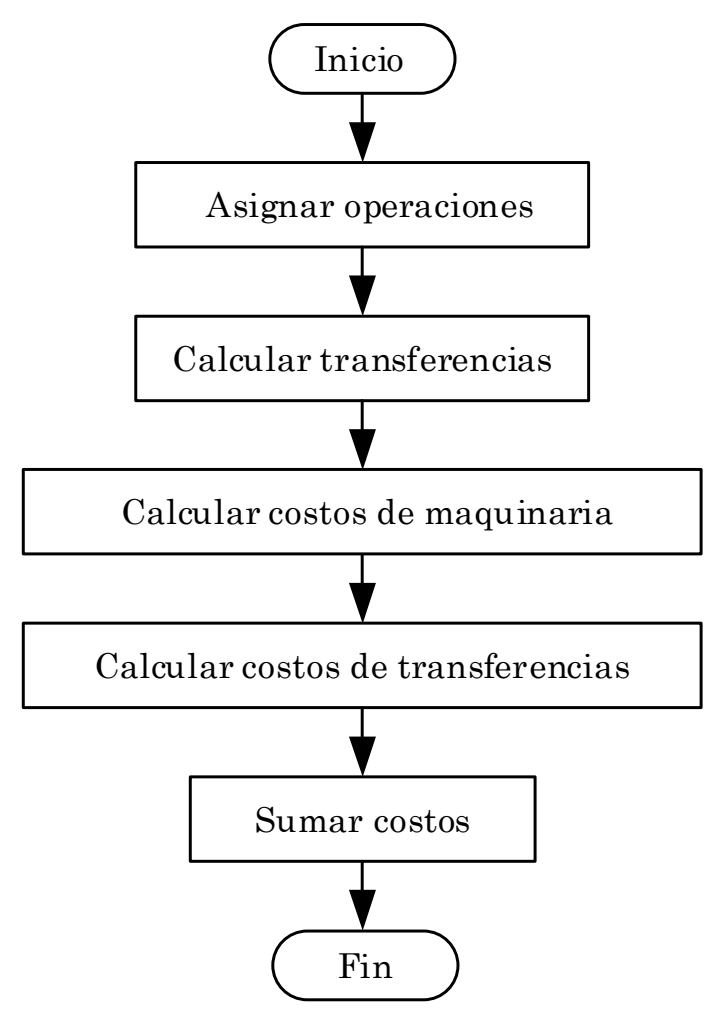

Fig. 5. Estructura del Módulo 4. Fuente: Autores. 


\section{Módulo 5: Improvisación}

Para cada iteración en el módulo de improvisación, el primer paso es identificar la peor y mejor solución almacenada en el vector; posteriormente se selecciona de manera aleatoria una solución almacenada en el vector de memoria, el segundo paso es determinar de manera aleatoria si se va a aplicar una improvisación a la respuesta tomando como criterio el parámetro HMRC, si no se improvisa, el tercer paso es generar una nueva solución de manera aleatoria que cumpla con las restricciones utilizando el Módulo 3; el cuarto paso es buscar y comparar la solución generada en el Módulo 3 con la mejor solución almacenada en el vector de memoria y seleccionar como respuesta o nueva armonía la mejor de las dos.

Si se improvisa, el quinto paso es determinar de manera aleatoria si se va a improvisar afinando; para ello se toma como criterio el parámetro PAR, si no se afina, se aplica el cuarto paso sólo que sin la necesidad de generar una solución usando el Módulo 3, si se afina, el sexto paso es modificar sutilmente el número de máquinas en cada celda generando una nueva solución; si esta nueva solución no cumple las restricciones se realiza un séptimo paso, el cual consiste en seleccionar como nueva armonía la mejor solución almacenada hasta el momento. Caso contrario si la nueva solución cumple con las restricciones, la nueva solución generada pasa a ser la nueva armonía. Finalmente, se busca en el vector de memoria la peor solución y se cambia esa solución con la nueva armonía obtenida mediante la improvisación. El proceso de improvisación se encuentra en la Fig. 6.

\section{Prueba del Modelo}

La ejecución del modelo se realiza con seis problemas o instancias, las cuales son adaptadas de los datos presentados [6], [27] mediante la generación de datos aleatorios relacionados con diferentes parámetros (demanda, número de operaciones por producto, número de máquinas específicas para cada operación, tiempos de operación y costos de las máquinas); los atributos son resumidos en la Tabla 1 y Tabla 2, además, en la Tabla 3 se especifican las cotas superiores e inferiores de las variables de diseño de la celda. El modelo matemático es resuelto mediante un método exacto con el fin de obtener el valor óptimo de referencia a contrastar con la metaheurística BA. El método exacto se desarrolla como un modelo de programación lineal entera mixta utilizando la herramienta de modelización algebraica general GAMS/CPLEX.

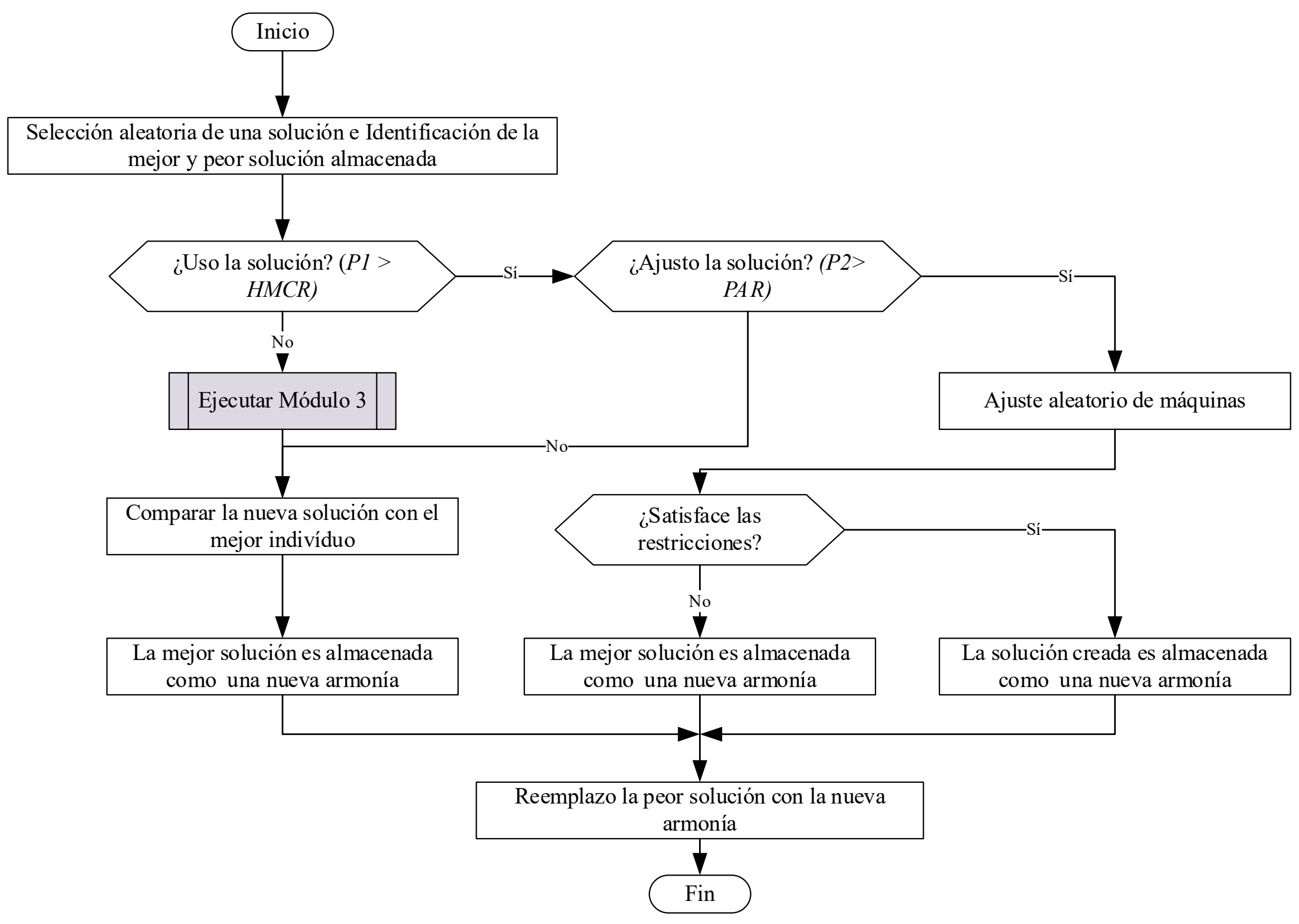

Fig. 6. Estructura del Módulo 5. Fuente: Autores. 
Para tal fin, se acoge la estructura básica de modelado de la herramienta que consta de 5 elementos: conjuntos, datos, variables, ecuaciones, y las declaraciones del modelo y de la solución del mismo. Para obtener la solución es utilizado un procesador Intel® core $^{\mathrm{TM}}$ i7-4790 CPU @3.60 GHz con memoria RAM 8.00 GB. Se resalta que durante el presente trabajo se obtiene la solución óptima de las diferentes instancias diseñadas.

TABla 1. CARACTERIZACión DE LOS PRoblemas tratados.

\begin{tabular}{|c|c|c|c|c|c|c|}
\hline Atributo & P1 & P2 & P3 & P4 & P5 & P6 \\
\hline Productos & 20 & 20 & 30 & 30 & 40 & 40 \\
\hline $\begin{array}{c}\text { Tipos de } \\
\text { Máquina }\end{array}$ & 10 & 10 & 15 & 15 & 20 & 20 \\
\hline No de Celdas $^{\circ}$ & 4 & 4 & 5 & 5 & 6 & 6 \\
\hline \multicolumn{7}{|c|}{ Fuente: Autores }
\end{tabular}

TABla 2. Distribución DE PROBABILIDAd EMPÍRICA PARA EL NÚMERO DE OPERACIONES POR TIPO DE PRODUCTO.

\begin{tabular}{|c|c|}
\hline $\begin{array}{c}\text { Número de } \\
\text { Operaciones }\end{array}$ & Probabilidad \\
\hline 2 & 30 \\
\hline 3 & 30 \\
\hline 4 & 20 \\
\hline 5 & 10 \\
\hline 6 & 10 \\
\hline
\end{tabular}

Fuente: Autores.

TABLA 3. Estructura PARA LA CARACTERIZACIÓN DE LOS PROBLEMAS A TRATAR.

\begin{tabular}{|c|c|c|}
\hline Variable & Tipo & Valor \\
\hline No. de operaciones & Distr. Empírica & Tabla 2 \\
\hline Demanda & Uniforme discreta & $\mathrm{U}(10,25)$ \\
\hline Tipo de máquina & Uniforme discreta & $\mathrm{U}(1, \mathrm{M})$ \\
\hline Tiempo de operación & Uniforme discreta & $\mathrm{U}(1,10)$ \\
\hline Costo de máquina & Uniforme discreta & $\mathrm{U}(100,2000)$ \\
\hline $\begin{array}{c}\text { Tiempo disponible de } \\
\text { máquina }\end{array}$ & Constante & $480(\mathrm{hr})$ \\
\hline $\begin{array}{c}\text { Costo transporte } \\
\text { intercelular }\end{array}$ & Constante & 1 \\
\hline $\begin{array}{c}\text { Tamaño de celda } \\
\text { Constante }\end{array}$ & $\begin{array}{c}\text { Min }=2 ; \\
\text { Max }=10\end{array}$ \\
\hline
\end{tabular}

Fuente: Autores.

Para el desarrollo del método aproximado BA, se ejecuta un código de MATLAB 2017a en máquinas con procesador Intel ${ }^{\circledR}$ core $^{\mathrm{TM}}$ i7-4790 CPU @3.60 $\mathrm{GHz}$ con memoria RAM 8.00 GB para un sistema operativo Windows 8.1 con estructura de 64 bits. Se realizan 20 réplicas en paralelo usando 12 máquinas con iguales especificaciones técnicas. Una vez finalizadas las réplicas, son recogidos los datos de manera aleatoria configurando así los 240 resulta- dos para cada instancia. Con el fin de determinar la eficacia del algoritmo metaheurístico aplicado, se propone un análisis de varianza (ANOVA) al tiempo y error promedio, para ello se tienen en cuenta dos factores \{Instancia, Estrategia\} cada uno con seis y dos niveles respectivamente, generando así doce tratamientos diferentes.

La ejecución de cada instancia es realizada en orden aleatorio de la siguiente manera: Instancia 1. Instancia 5. Instancia 2. Instancia 6. Instancia 4 e Instancia 3. Los datos fueron analizados utilizando Minitab® 17.2.1 en un computador con iguales especificaciones.

\section{Resultados}

En la Tabla 4, se registran los parámetros generales de las instancias trabajadas con el modelo de asignación de máquinas y la metaheurística BA. Por otra parte, en la Fig. 7 están las salidas del ANOVA donde se compara el error obtenido por las dos estrategias de asignación aleatoria de máquinas (estrategias descritas en el Módulo 4). Los p-valores resultantes indican que existen diferencias significativas entre los tipos de estrategia de asignación y la instancia solucionada ( $p$-valor $\leq 0.05$ ). De hecho, al observar los datos consignados en la Tabla 5, se encuentra que la estrategia aleatoria modificada presenta menor error promedio.

Por otra parte, en la Fig. 8 se registran los respectivos valores del análisis estadístico según el tiempo de cómputo requerido para terminar las improvisaciones; encontrando que existen diferencias estadísticas entre los factores bajo estudio, según los resultados registrados en la Tabla 5 se determina que la estrategia de asignación modificada es más veloz en comparación con la asignación aleatoria tradicional.

TABLA 4. Resultados DE LA BÚSQUEDA ARMÓNICA PARA LAS SEIS INSTANCIAS PROPUESTAS.

\begin{tabular}{|c|c|c|c|c|c|c|c|c|c|}
\hline 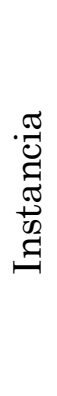 & 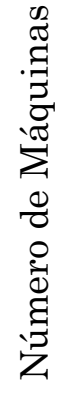 & 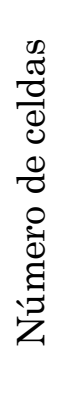 & 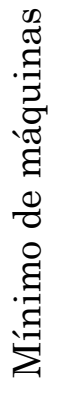 & 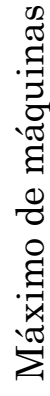 & 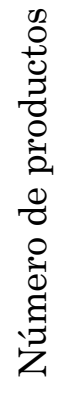 & 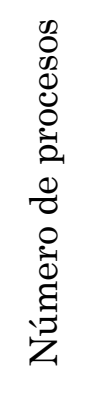 & 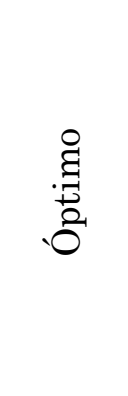 & 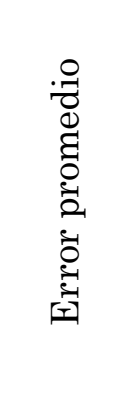 & 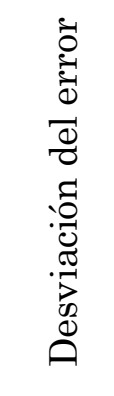 \\
\hline 1 & 10 & 4 & 2 & 10 & 20 & 70 & 20618 & $1,06 \%$ & $0,09 \%$ \\
\hline 2 & 10 & 4 & 2 & 10 & 20 & 70 & 15525 & $1,22 \%$ & $0,12 \%$ \\
\hline 3 & 15 & 5 & 2 & 10 & 30 & 113 & 25244 & $2,51 \%$ & $0,10 \%$ \\
\hline 4 & 15 & 5 & 2 & 10 & 30 & 109 & 30354 & $1,81 \%$ & $0,08 \%$ \\
\hline 5 & 20 & 6 & 2 & 10 & 40 & 141 & 41829 & $1,80 \%$ & $0,06 \%$ \\
\hline 6 & 20 & 6 & 2 & 10 & 40 & 126 & 33010 & $1,39 \%$ & $0,06 \%$ \\
\hline
\end{tabular}

Fuente: Autores. 


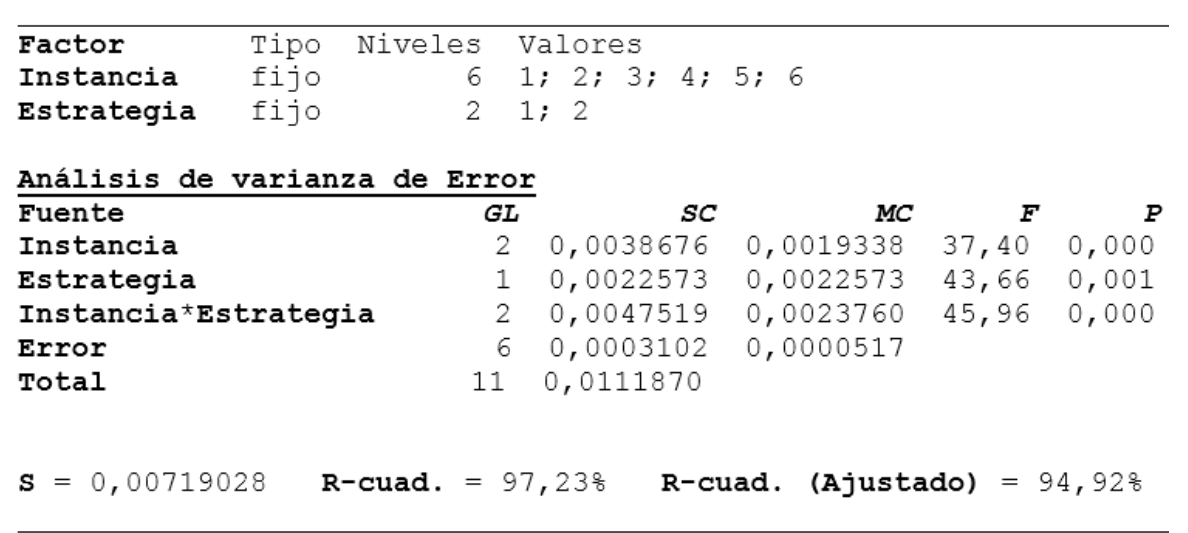

Fig. 7. Análisis de varianza para el error de las dos estrategias de asignación de máquinas. Fuente: Autores.

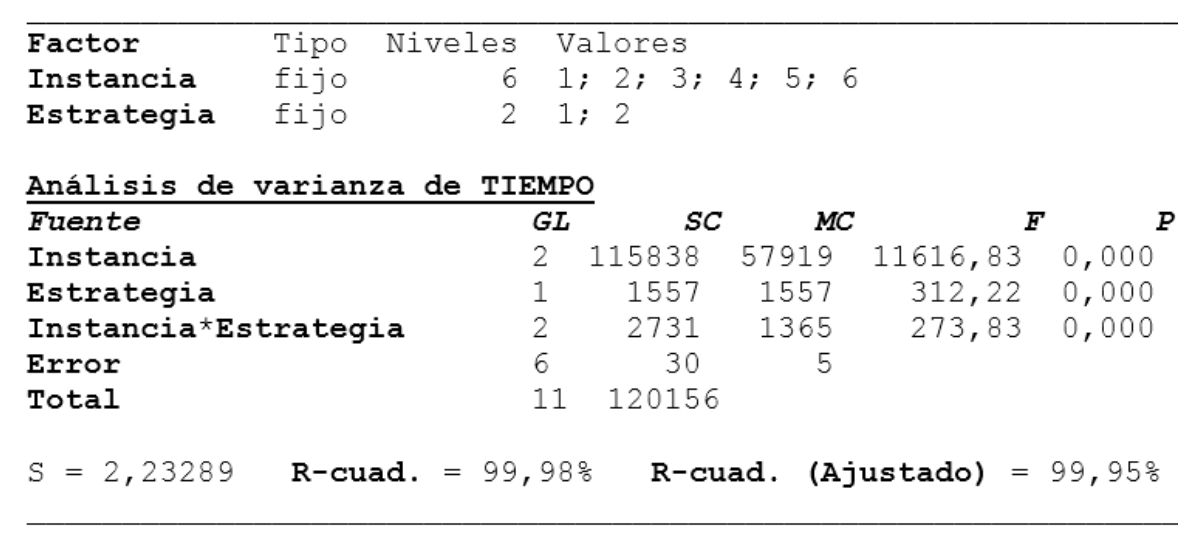

Fig. 8. Análisis de varianza para el tiempo de las dos estrategias de asignación de máquinas. Fuente: Autores.

TABla 5. Resultados comparativos entre las dos estrategias DE SOLUCIÓN.

\begin{tabular}{|c|c|c|c|}
\hline Instancia & Error & Tiempo & Estrategia de asignación \\
\hline 1 & $1,23 \%$ & 40,42 & Uniforme tradicional \\
\hline 2 & $1,36 \%$ & 39,76 & Uniforme tradicional \\
\hline 3 & $2,63 \%$ & 64,56 & Uniforme tradicional \\
\hline 4 & $2,74 \%$ & 63,12 & Uniforme tradicional \\
\hline 5 & $1,47 \%$ & 290,48 & Uniforme tradicional \\
\hline 6 & $1,44 \%$ & 292,48 & Uniforme tradicional \\
\hline 1 & $1,32 \%$ & 43,74 & Uniforme Modificada \\
\hline 2 & $1,68 \%$ & 42,42 & Uniforme Modificada \\
\hline 3 & $1,94 \%$ & 54,12 & Uniforme Modificada \\
\hline 4 & $2,75 \%$ & 61,12 & Uniforme Modificada \\
\hline 5 & $8,66 \%$ & 225,56 & Uniforme Modificada \\
\hline 6 & $10,98 \%$ & 227,17 & Uniforme Modificada \\
\hline
\end{tabular}

Fuente: Autores.

Teniendo en cuenta los resultados obtenidos en los Análisis de varianza de la Fig. 7 y la Fig. 8 en conjunto con los valores medios descritos en la Tabla 5, se concluye que existen diferencias significativas en los resultados de cómputo (error y tiempo) según las estrategias de asignación de máquinas, encontrando que la variable uniforme modificada logra mejores tiempos para hallar la solución, pero a costa de un error más grande. Ahora bien, se demuestra además que las dos variantes del método aproximado propuesto logran buenas soluciones en un tiempo computa- cional aceptable ya que los reportes finales arrojados por GAMS se tardan aproximadamente 8800 segundos, lo cual demuestra que, debido a la memoria de almacenamiento limitada el CPLEX no es capaz de continuar su exploración y por tanto se finaliza la búsqueda indicando la mejor respuesta encontrada. En otras palabras, dependiendo de la instancia la memoria RAM del computador utilizado no tiene la capacidad suficiente para poder resolver problemas del tamaño propuesto, lo que no es raro cuando se trata de problemas de programación entera mixta, y para lo cual existen algunas alternativas de solución como la desarrollada en la presente investigación.

\section{CONCLUSIONES}

La presente investigación evidencia la pertinencia de buscar formas de resolver problemas complejos a través de técnicas que permitan encontrar soluciones prácticas en tiempos computacionales razonables y enfocados a entornos de manufactura reales. Más aún, si se consideran los avances asociados a la integración tecnológica que exigen una mayor rapidez en la reconfiguración de estos sistemas para dar respuesta de manera oportuna a los desafíos que el mercado impone. En consecuencia, en este trabajo fue desarrollado un algoritmo metaheurístico Búsqueda Armónica para abordar el problema de formación de celdas de manufactura.

Parte de los resultados del trabajo incluye una mejora en la naturaleza del algoritmo, el cual se enfoca en la explotación del espacio de búsqueda al considerar siempre la mejor solución obtenida cuando se presentaban soluciones no factibles, concentrando así el espacio de búsqueda. Dicho cambio aprovecha la estructura computacional y el uso de recursos, puesto que la Búsqueda Armónica tradicional sólo acepta una nueva respuesta si ésta es mejor que la peor almacenada, de forma tal que, si no satisface esa condición, el tiempo dedicado a hallar dicha mejora es desaprovechado. Ahora bien, es necesario para futuros trabajos agregar estrategias de exploración del espacio de búsqueda, es por ello que se propone la generación de subconjuntos o submelodías de manera independiente con el fin de evitar concentrar excesivamente el espacio de búsqueda, lo que puede conllevar a encontrar una solución tipo óptimo local.

Además, dentro del desarrollo del algoritmo para la solución aproximada, como estrategia para mejorar la convergencia de aquellas variables de decisión tipo binaria (si la operación $j$ del producto $p$ es fabricada en la máquina tipo $m$ se puede realizar en más de una celda $c$ por ejemplo) se realizan asignaciones aleatorias e independientes de manera simultánea, estas se comparan entre sí con el fin de escoger aquella configuración que conlleve a menores costos de transferencias entre celdas, proceso similar a una rápida búsqueda exhaustiva. 
Por otra parte, si bien la variabilidad de las respuestas para cada instancia es notoria, el rango de error es bajo, normalmente entre el $1 \%$ a $2 \%$, dicha tendencia se traduce en la efectividad de la Búsqueda Armónica para celdas de manufactura. Además, el modelo eventualmente puede generar muy buenas respuestas en corto tiempo ya que durante la experimentación se encontraron algunos datos atípicos con errores y tiempo considerablemente menores.

De otra parte, teniendo en cuenta la distribución de los errores de estimación obtenidos, al revisar las estrategias de llenado de celda, se concluye que es necesario para futuros trabajos en los que se realicen variaciones en el flujo de productos entre celdas o la posible configuración de celdas (como celdas dinámicas, virtuales, entre otras), reevaluar los valores de los parámetros de la metaheurística (como el ajuste de tono, número de iteraciones, etc.), lo anterior con el fin de no sacrificar exactitud por tiempo de respuesta.

Finalmente, considerando el nivel de desarrollo que se ha logrado en los sistemas de manufactura, particularmente en sistemas flexibles de respuesta rápida al usuario y alineados a estrategias como la personificación masiva, es de vital importancia responder desde la ingeniería de planta a estos desafíos, los cuales incluyen los aspectos técnicos de diseño del sistema productivo. Una de estas estrategias es a partir del desarrollo de algoritmos computacionales que permitan hallar soluciones prácticas en tiempos razonables, como apoyo a la toma de decisiones, modeladas mediante programación matemática. En tal sentido, es pertinente para futuras investigaciones la realización de trabajos enfocados en el tratamiento no sólo de modelado matemático sino también de técnicas complementarias de solución que evolucionen hacia herramientas agiles para los procesos de toma de decisiones a este nivel, como la implementación de este tipo de soluciones en múltiples plataformas como Web, Desktop o Mobile.

\section{REFERENCIAS}

[1] R. Kumar, S. P. Singh and K. Lamba, "Sustainable Robust Layout using Big Data approach: A Key towards Industry 4.0," J. Clean. Prod., vol. 204, 643-659, Sep. 2018. https:// doi.org/10.1016/j.jclepro.2018.08.327

[2] S. S. Heragu, "Group technology and cellular manufacturing," IEEE Trans. Syst. Man. Cybern., vol. 24, no. 2, pp. 203-215, Feb. 1994. https://doi.org/10.1109/21.281420

[3] A. I. Abduelmola and S. M. Taboun, "A simulated annealing algorithm for designing cellular manufacturing systems with productivity consideration," Prod. Plan. Control, vol. 11, no. 6, pp. 589-597, Jan. 2000. https://doi. org/10.1080/095372800414151

[4] N. L. Hyer and K. A. Brown, "The Discipline of real cells," J. Oper. Manag., vol. 17, no. 5, pp. 557-574, Jul. 1999. https://doi.org/10.1016/S0272-6963(99)00003-0
[5] J. Wang and C. Roze, "Formation of machine cells and part families: A modified p-median model and a comparative study," Int. J. Prod. Res., vol. 35, no. 5, pp. 1259-1286, May. 1997. https://doi.org/10.1080/002075497195317

[6] A. Kusiak and W. S. Chow, "Decomposition of manufacturing systems," IEEE J. Robot. Autom., vol. 4, no. 5, pp. 457-471, Oct. 1988. https://doi.org/10.1109/56.20430

[7] A. Mungwattana, "Design of cellular manufacturing systems for dynamic and uncertain production requirements with presence of routing flexibility," Ph.D. dissertation, Fac. ISE., VPI, Blacksburg, Virginia, 2000.

[8] N. Singh, "Design of cellular manufacturing systems: An invited review," Eur. J. Oper. Res., vol. 69, no. 3, pp. 284-291, Sep. 1993. https://doi.org/10.1016/03772217(93)90016-G

[9] Z. W. Geem, Ed., Music-inspired harmony search algorithm: theory and applications. Heidelberg, Germany: Springer, 2009. https://doi.org/10.1007/978-3-642-001857

[10] Y. Li, X. Li and J. N. D. Gupta, "Expert Systems with Applications Solving the multi-objective flowline manufacturing cell scheduling problem by hybrid harmony search,” Expert Syst. Appl., vol. 42, no. 3, pp. 1409-1417, Feb. 2015. https://doi.org/10.1016/j.eswa.2014.09.007

[11] K. Z. Gao, P. N. Suganthan, Q. K. Pan, T. J. Chua, T. X. Cai and C. S. Chong, "Pareto-based grouping discrete harmony search algorithm for multi-objective flexible job shop scheduling," Inf. Sci. (Ny)., vol. 289, pp. 76-90, Dec. 2014. https://doi.org/10.1016/j.ins.2014.07.039

[12] K. Z. Gao, P. N. Suganthan, Q. K. Pan, T. J. Chua, T. X. Cai \& C. S. Chong, "Discrete harmony search algorithm for flexible job shop scheduling problem with multiple objectives," J. Intell. Manuf., pp. 363-374, Apr. 2016. https:// doi.org/10.1007/s10845-014-0869-8

[13] K. Nekooei, M. M. Farsangi, H. Nezamabadi-pour and K. Y. Lee, "An Improved Multi-Objective Harmony Search for Optimal Placement of DGs in Distribution Systems," IEEE Trans. Smart Grid, vol. 4, no. 1, pp. 557-567, Mar. 2013. https://doi.org/10.1109/TSG.2012.2237420

[14] J. R. King and V. Nakornchai, "Machine-component group formation in group technology: review and extension," Int. J. Prod. Res., vol. 20, no. 2, pp. 117-133, Apr. 2007. https://doi.org/10.1080/00207548208947754

[15] J. R. King, "Machine-component grouping in production flow analysis: an approach using a rank order clustering algorithm," Int. J. Prod. Res., vol. 18, no. 2, pp. 213-232, Apr. 1980. https://doi.org/10.1080/00207548008919662

[16] H. Seifoddini and B. Tjahjana, "Part-family formation for cellular manufacturing: A case study at Harnischfeger," Int. J. Prod. Res., vol. 37, no. 14, pp. 3263-3273, Sep. 1999. https://doi.org/10.1080/002075499190275

[17] C. Dimopoulus and N. Mort, "Evolving similarity coefficients for the solution of cellular manufacturing problems," in Proc. Congr. Evol. Comput., CEC 2000, La Jolla, CA, USA, 16-19 Jul. 2000, pp. 617-624. https://doi. org/10.1109/CEC.2000.870355

[18] J. McAuley, "Machine grouping for efficient production," Prod. Eng., vol. 51, no. 2, pp. 53-57, Feb. 1972. https://doi. org/10.1049/tpe.1972.0006

[19] H. Seifoddini and P. M. Wolfe, "Application of the Similarity Coefficient Method in Group Technology," IIE Trans., vol. 18, no. 3, pp. 271-277, Sep. 1986. https://doi. org/10.1080/07408178608974704

[20] G. Srinivasan and T. T. Narendran, "GRAFICS-a nonhierarchical clustering algorithm for group technology," Int. J. Prod. Res., vol. 29, no. 3, pp. 463-478, Mar. 1991. https://doi.org/10.1080/00207549108930083 
[21] M. Chandrasekharan and R. Rajagopalan, "ZODIAC-an algorithm for concurrent formation of part-families and machine-cells," Int.J.Prod.Res.,vol.25, no.6, pp.835-850, Jun. 1987. https://doi.org/10.1080/00207548708919880

[22] M. Chandrasekharan and R. Rajagopalan, "An ideal seed non-hierarchical clustering algorithm for cellular manufacturing," Int. J. Prod. Res., vol. 24, no. 2, pp. 451-463, Mar. 1986. https://doi.org/10.1080/00207548608919741

[23] A. Kusiak, "The generalized group technology concept," Int. J. Prod. Res., vol. 25, no. 4, pp. 561-569, Apr. 1987. https://doi.org/10.1080/00207548708919861

[24] S. Nicoletti, G. Nicosia and A. Pacifici, "Group Technology with Flow Shop Cells," in Theory and Practice of Control and Systems. Singapur: World Scientific Publishing, 1999, pp. 800-804. https://doi. org/10.1142/9789814447317_0133

[25] Z. Y. Lim, S. G. Ponnambalam and K. Izui, "Multi-objective hybrid algorithms for layout optimization in multirobot cellular manufacturing systems," KnowledgeBased Syst., vol. 120, pp. 87-98, Mar. 2017. https://doi. org/10.1016/j.knosys.2016.12.026

[26] M. Diaby and A. L. Nsakanda, "Large-scale capacitated part-routing in the presence of process and routing flexibilities and setup costs," J. Oper. Res. Soc., vol. 57, no. 9, pp. 1100-1112, Sep. 2006. https://doi.org/10.1057/palgrave.jors. 2602072

[27] H. Djellab and M. Gourgand, "A new heuristic procedure for the single-row facility layout problem," Int. J. Comput. Integr. Manuf., vol. 14, no. 3, pp. 270-280, Jan. 2001. https://doi.org/10.1080/09511920010020721

[28] M. Z. Allahyari and A. Azab, "A Novel Bi-level Continuous Formulation for the Cellular Manufacturing System Facility Layout Problem," Procedia CIRP, vol. 33, pp. 8792, Dec. 2015. https://doi.org/10.1016/j.procir.2015.06.017

[29] S. P. Darla, C. D. Naiju, P. V. Sagar and B. Linkhit, "Optimization of Inter Cellular Movement of Parts in Cellular Manufacturing System Using Genetic Algorithm Optimization of Inter Cellular Movement of Parts in Cellular Manufacturing System Using Genetic Algorithm," Res. J. Appl. Sci. Eng. Technol., vol 7, no. 1, pp. 165-168, Jan. 2014. https://doi.org/10.19026/rjaset.7.235

[30] M. Aghajani, A. Keramati, R. T. Moghadam and S. S. Mirjavadi, "A mathematical programming model for cellular manufacturing system controlled by kanban with rework consideration," Int. J. Adv. Manuf. Technol., vol. 82, pp. 1377-1394, Mar. 2016. https://doi.org/10.1007/ s00170-015-7635-8

[31] Y. B. Sahin and S. Alpay, "A metaheuristic approach for a cubic cell formation problem," Expert Syst. Appl., vol. 65, pp. 40-51, Dec. 2016. https://doi.org/10.1016/j. eswa.2016.08.034

[32] S. Shahdi-Pashaki, E. Teymourian and R. TavakkoliMoghaddam, "New approach based on group technology for the consolidation problem in cloud computing-mathematical model and genetic algorithm," Comput. Appl. Math., vol. 37, no. 1, pp. 693-718, Jul. 2016. https://doi. org/10.1007/s40314-016-0362-4

[33] R. Maleki, S. Ketabi and F. M. Rafiei, "Grouping both machines and parts in cellular technology by Genetic Algorithm," J. Ind. Prod. Eng., vol. 35, no. 2, pp. 91-101, Feb. 2018. https://doi.org/10.1080/21681015.2017.141140 2

[34] H. Feng, T. Xia, W. Da, L. Xi and E. Pan, "Concurrent design of cell formation and scheduling with consideration of duplicate machines and alternative process routings," J. Intell. Manuf., vol. 30, no. 1, pp. 275-289, Jan. 2019. https://doi.org/10.1007/s10845-016-1245-7
[35] V. Jayakumar and J. Raju, "A Simulated Annealing Algorithm for Machine Cell Formation Under Uncertain Production Requirements," AJSE, vol. 39, pp. 73457354, Aug. 2014. https://doi.org/10.1007/s13369-0141306-1

[36] C. Liu and J. Wang, "Cell formation and task scheduling considering multi-functional resource and part movement using hybrid simulated annealing," Int. J. Comput. Intell. Syst., vol. 9, no. 4, pp. 765-777, Aug. 2016. https://doi.org/10.1080/18756891.2016.1204123

[37] F. Shafigh, F. M. Defersha and S. Eid, "A linear programming embedded simulated annealing in the design of distributed layout with production planning and systems reconfiguration," Int. J. Adv. Manuf. Technol., vol. 88, pp. 1119-1140, May. 2016. https://doi.org/10.1007/ s00170-016-8813-z

[38] A. Iqbal and K. A. Al-Ghamdi, "Energy-efficient cellular manufacturing system: Eco-friendly revamping of machine shop configuration," Energy, vol. 163, pp. 863-872, Nov. 2018. https://doi.org/10.1016/j.energy.2018.08.168

[39] Y. Gholipour-Kanani, I. R. Tavakkoli-Moghaddam and I. A. Khorrami, "Solving a multi-criteria group scheduling problem for a cellular manufacturing system by scatter search," JCIIE, vol. 28, no. 3, pp. 192-205, Feb. 2011. https://doi.org/10.1080/10170669.2010.549663

[40] M. S. Jabal-Ameli and M. Moshref-Javadi, "Concurrent cell formation and layout design using scatter search," Int. J. Adv. Manuf. Technol., vol. 71, pp. 1-22, Mar. 2014. https://doi.org/10.1007/s00170-013-5342-x

[41] A. S. Amiri and R. Ghodsi, "A variable neighborhood search method for an integrated cellular manufacturing systems with production planning and system reconfiguration," in 4th Int. Conf. Math. Model. Comput. Simul., AMS2010, Bornea, Malaysia, 26-28 May. 2010, pp. $181-186$.

[42] F. Jolai, M. Taghipour and B. Javadi, "A variable neighborhood binary particle swarm algorithm for cell layout problem," Int. J. Adv. Manuf. Technol., vol. 55, no. 1-4, pp. 327-339, Jul. 2011. https://doi.org/10.1007/s00170010-3039-y

[43] S.-H. Chung, T.-H. Wu and Ch.-Ch. Chang, "An efficient tabu search algorithm to the cell formation problem with alternative routings and machine reliability considerations," Comput. Ind. Eng., vol. 60, no. 1, pp. 7-15, Feb. 2011. https://doi.org/10.1016/j. cie. 2010.08 .016

[44] J. J. Du, G. X. Wang, Y. Yan and Q. Sang, "Tabu Search-based Formation of Reconfigurable Manufacturing Cells," Appl. Mech. an Mater., vol. 397-400, no. 1, pp. 34-41, Sept. 2013. https://doi.org/10.4028/www. scientific.net/AMM.397-400.34

[45] F. Sarayloo and R. Tavakkoli-Moghaddam, "Multi Objective Particle Swarm Optimization for a Dynamic Cell Formation Problem," in World Congr. Eng. vol. III, WCE 2010, London, UK, Jun. 30 - Jul. 2, 2010.

[46] A. Azadeh, S. Pashapour and S. A. Zadeh, "Designing a cellular manufacturing system considering decision style, skill and job security by NSGA-II and response surface methodology," Int. J. Prod. Res., vol. 54, no. 22, pp. $6825-6847$, May. 2016. https://doi.org/10.1080/0020 7543.2016.1178407

[47] K. S. Lee and Z. W. Geem, "A new meta-heuristic algorithm for continuous engineering optimization: harmony search theory and practice," Comput. Methods Appl. Mech. Eng., vol. 194, no. 36-38, pp. 3902-3933, Sep. 2005. https://doi.org/10.1016/j.cma.2004.09.007 
[48] J. Arkat, M. H. Farahani and F. Ahmadizar, "Multiobjective genetic algorithm for cell formation problem considering cellular layout and operations scheduling," Int. J. Comput. Integr. Manuf., vol. 25, no. 7, pp. 625-635, Jul. 2012. https://doi.org/10.1080/095119 2X.2012.665182

[49] M. Solimanpur, P. Vrat and R. Shankar, "Ant colony optimization algorithm to the inter-cell layout problem in cellular manufacturing," Eur. J. Oper. Res., vol. 157, no. 3, pp. 592-606, Sep. 2004. https://doi.org/10.1016/S03772217(03)00248-0

[50] A. J. Vakharia and Y.-L. Chang, "Cell formation in group technology: A combinatorial search approach," Int. J. Prod. Res., vol. 35, no. 7, pp. 2025-2044, Jul. 1997. https://doi.org/10.1080/002075497195056

[51] B. P. Ahmed, R. Tavakkoli-Moghaddam and N. Safaei, "A comparison of heuristic methods for solving a cellular manufacturing model in a dynamic environment," UOW, Wolv., UK, WP007/04, 2004.

[52] F. S. Hillier and G. Lieberman, Introducción a la Investigación de Operaciones. 9 ed. México, D.F.: McGraw-Hill, 1997.

[53] Z. Yang, "Analysis and Design of Cellular Manufacturing Systems: Machine-Part Cell Formation and Operation Allocation," Ph.D. dissertation, CWRU, Cleveland, Ohio, USA, 1995.

[54] D. M. Himmelblau, Applied Nonlinear Programming, 1st ed. NY, USA: McGraw-Hill, 1972.
Edwin Alberto Garavito Hernández, M.Sc. en Ingeniería Industrial de la Universidad de Puerto Rico (Recinto Universitario Mayagüez, Puerto Rico). Ha estado vinculado a la Universidad Industrial de Santander-UIS (Colombia) como Profesor Tiempo Completo en el área de Diseño de Sistemas Productivos y Simulación discreta. Entre sus intereses de investigación están la optimización, métodos heurísticos, gestión de la producción, diseño de sistemas productivos y simulación, entre otros. https://orcid.org/0000-0002-0145-232X

Leonardo Hernán Talero Sarmiento, M.Sc. en Ingeniería Industrial de la Universidad Industrial de Santander (Colombia). Ha estado vinculado a la Universidad Industrial de Santander como becario de investigación en el grupo OPALO. Sus intereses de investigación son la gestión de la producción, finanzas, heurísticas y el análisis de modelos de causalidad en talento humano. https://orcid.org/0000-0002-4129-9163

Laura Yeraldín Escobar Rodríguez, Ingeniería Industrial de la Universidad Industrial de Santander, (Colombia). Está vinculada a la Universidad Industrial de Santander como becaria en investigación del grupo OPALO. Sus intereses de investigación son el Diseño de Sistemas Productivos, Gestión de la Producción, Optimización y Métodos Heurísticos. https://orcid.org/00000003-3350-9113 